WANL-TMI-085

L.B. WILKER

MAY 7, 1962

\title{
BINARY COUNTERS
}

\section{VOLUME 1, SECTION 2}

This report was prepoTICE

sponsored by the United as an account of work

the United States norted States Government Nerther

Research and Development United States Energy

therr employees,

subcontractors, nor any of their contractors,

warranty, express or their employees, makes any

labulity or respon or $1 \mathrm{mpl}$ ed, or assumes any any

or usefulness of any inf for the accuracy, completeness

process disclosed, or represents, apparatus, product or

infninge privately owned rights that its use would not 


\section{DISCLAIMER}

This report was prepared as an account of work sponsored by an agency of the United States Government. Neither the United States Government nor any agency Thereof, nor any of their employees, makes any warranty, express or implied, or assumes any legal liability or responsibility for the accuracy, completeness, or usefulness of any information, apparatus, product, or process disclosed, or represents that its use would not infringe privately owned rights. Reference herein to any specific commercial product, process, or service by trade name, trademark, manufacturer, or otherwise does not necessarily constitute or imply its endorsement, recommendation, or favoring by the United States Government or any agency thereof. The views and opinions of authors expressed herein do not necessarily state or reflect those of the United States Government or any agency thereof. 


\section{DISCLAIMER}

Portions of this document may be illegible in electronic image products. Images are produced from the best available original document. 


\section{BINARY COUNTERS}

\section{A. BINARY COUNTING}

The binary system of representing numbers has been outlined in Section 1, Introduction to Binary, and we shall now look at the binary system as used in relation with multivibrators to form binary counters. Binary counters find use in:

1. The direct counting of events

2. Direct measurement

3. Indirect measurements,

Frequency, time, speed, digital computers

As stated previously, multivibrators or binaries, are two tube devices which have two stable states (see sketch below). One state is designated by the binary number "O" and the other state by the binary numeral " 1 ". The section from which the output is obtained is called the output tube and unless otherwise noted, the output is usually taken from the plate of the right hand tube (RHP). Whenever the output is taken from the left hand tube, the binary is designated (LHP).

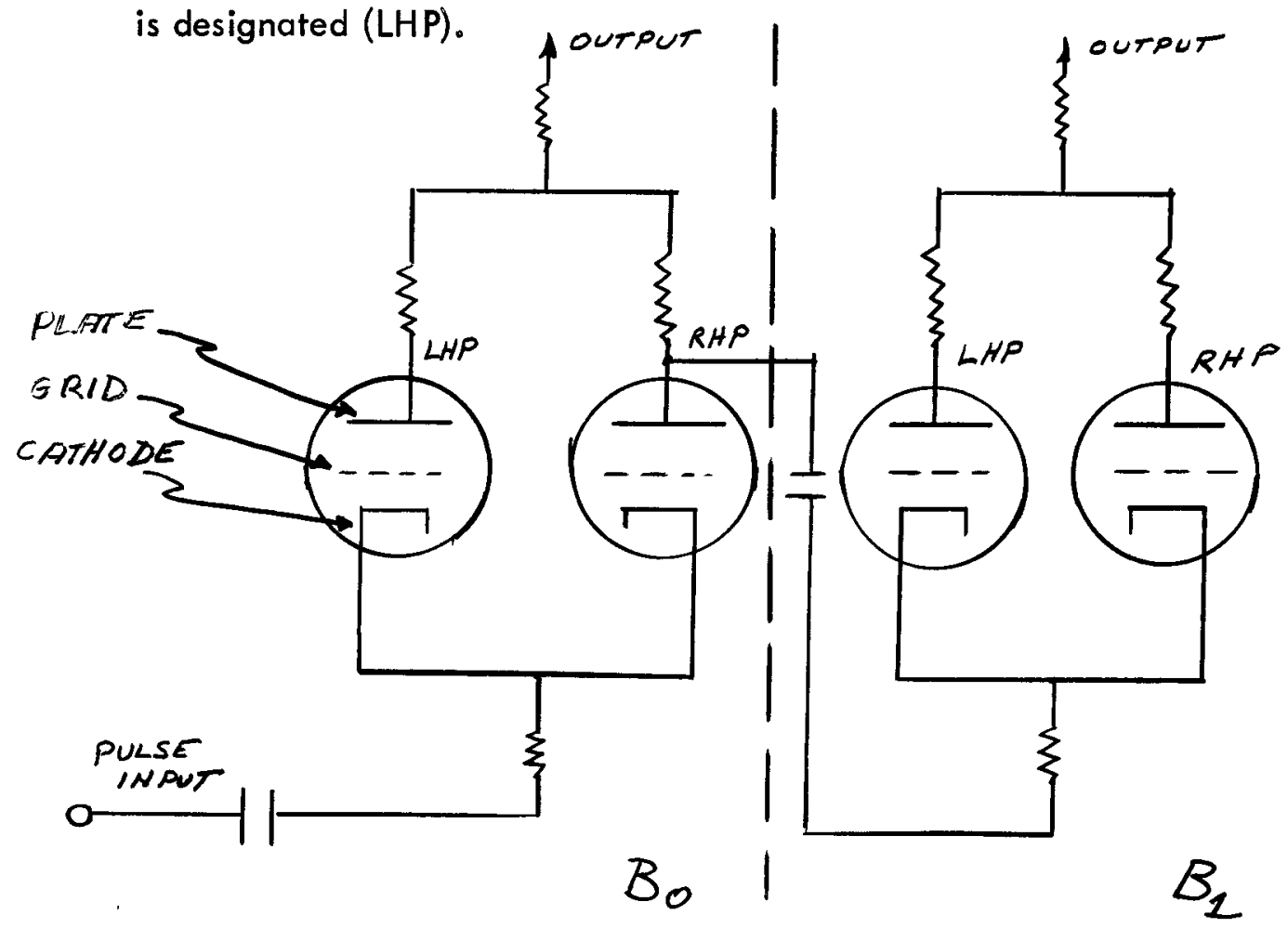




\section{B. SCALE-OF-4 COUNTER}

The binary chain of figure 1 constitutes a "scale-of-4" counter. The circuit has 4 different possible states and at the occasion of each input pulse the circuit will make a transition progressively from state to state. After 4 pulses the circuit will reset itself into its original state.

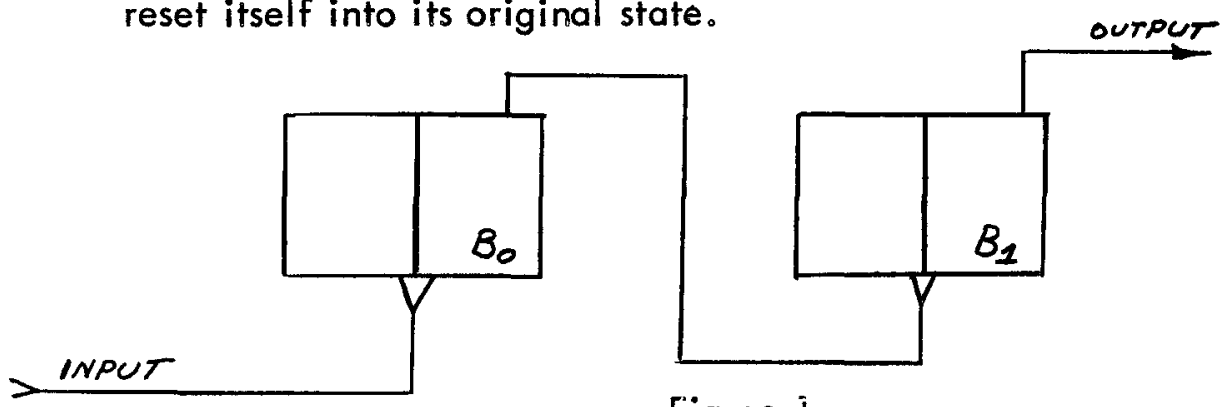

Figule i

The sequence of triggering pulses is fed in a symmetrical fashion into the first binary labeled $\mathrm{B}_{0}$. Output signal of the first binary (which is the signal that appears at the output plate of $B_{0}$ ) is applied symmetrically to the second binary $B_{1}$. B B will have a transition on each pulse. $B_{1}$ makes a transition only when the preceding binary goes from a " 1 " to a "0". Then $B_{1}$ will go from " 0 " to " 1 ".

This is due to the internal circuitry of the binary, which only changes state on a negative pulse. Thus, the only time a change of output plate voltage in $B_{0}$ affects the state of $B_{1}$ is when the plate voltage of $B_{0}$ drops. These features are easily recognized from the counter and waveform chart of figure $2 a, 2 b, 2 c, 2 d$, and $2 \mathrm{e}$.
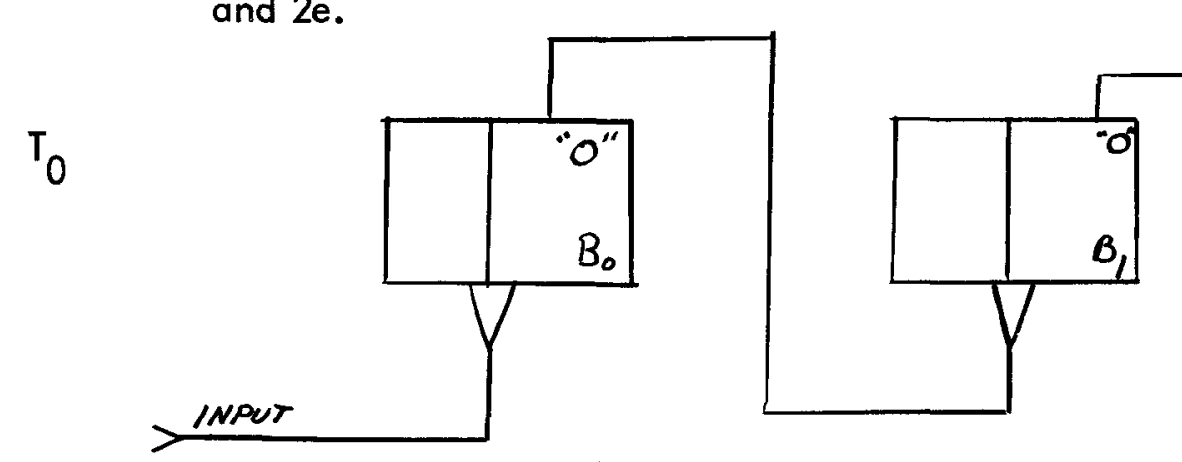

OUTPUT

At $T_{0}$ :

Both binaries are in a "O" state

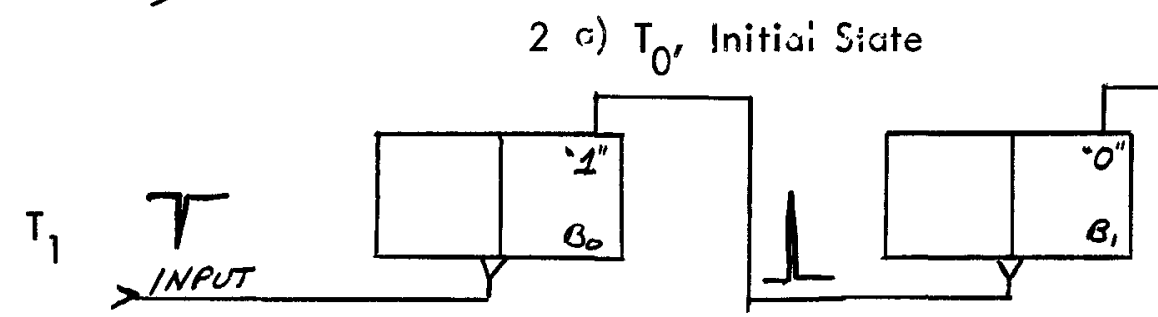

2 b) $T_{1}$, First Input Pulse

ourput

At $T_{1}$ :

The negative input pulse causes the plate of $B_{0}$ to go from a "O" state to a "l" state, causing a positive voltage change. The positive pulse goes through $B_{1}$ without any change to $B_{1}$. 
$\mathrm{T}_{2}$

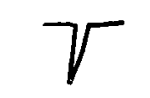

INPUT

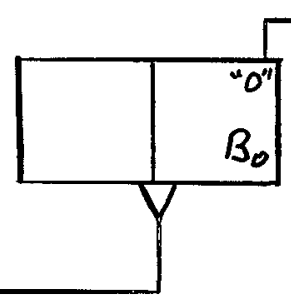

2 c) $T_{2}$, Second Input Puise

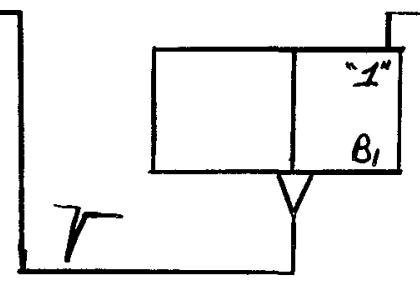

Output

The negative pulse causes the plate of $\mathrm{B}_{0}$ to go from a "1" state to a "0" state causing a negative pulse to go through $B_{1}$ and change its state from a "O" to a "l".

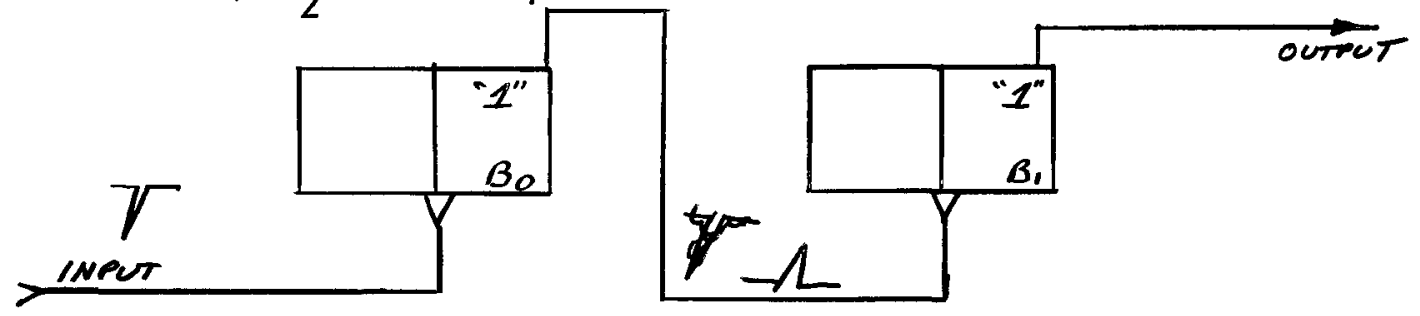

2 d) $\mathrm{T}_{3}$. Third Input Pulse

INPUT PULSES

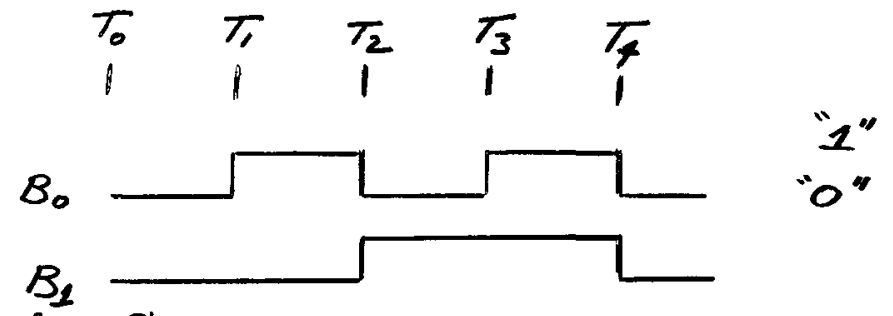

2 e) Waveform Chart.

Figuie $\angle$

\section{SCALE OF 16 COUNTER}

As seen in figure $3_{*}$ the binary chain counter consisting of 4 binaries has 16 possible different states. Consider the initial state of the combination of the binaries in which all four individual binaries are in state " 0 ". Beginning from this reference state, the waveforms which appear at the output plates of the multivibrators as a result of the application of 16 successive input pulses are shown in figure 3 .
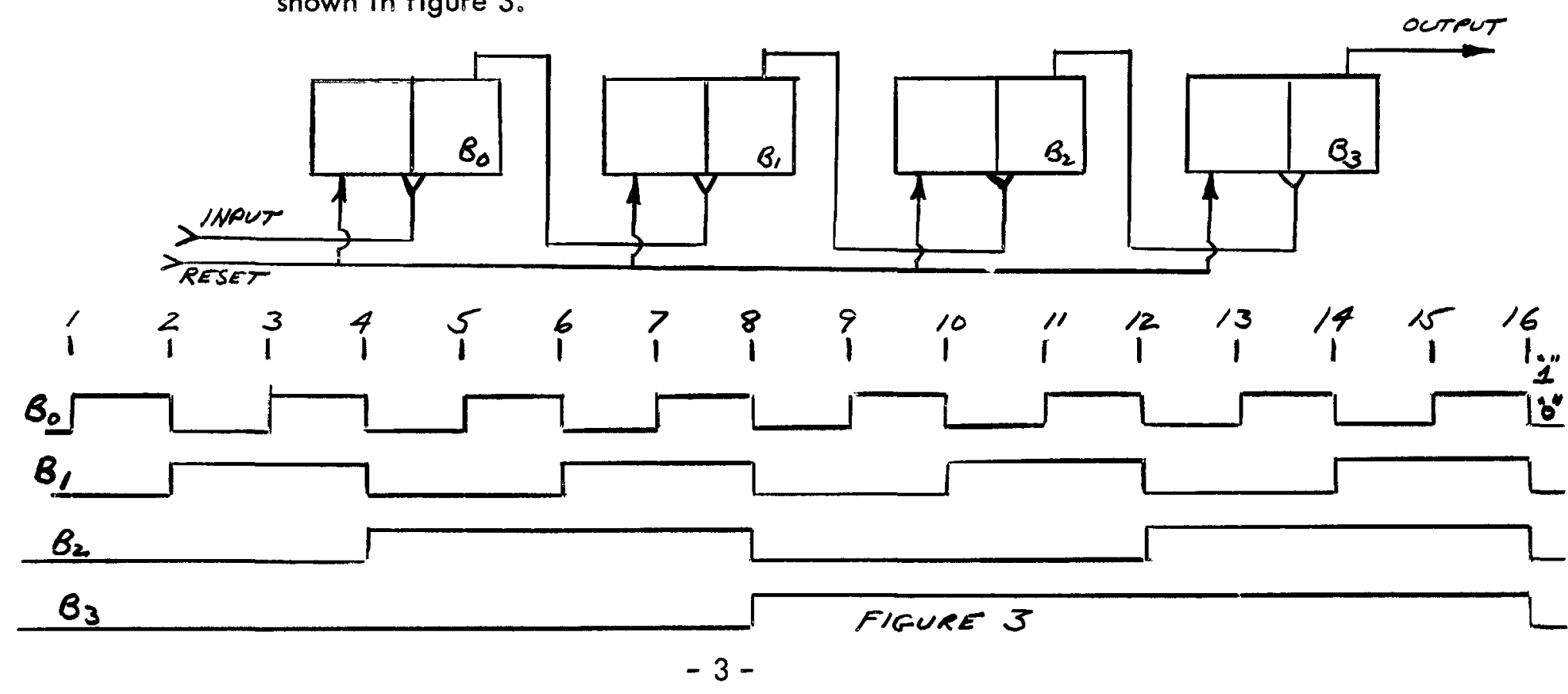
Table A - Decimal and Binary Numbers

$\frac{\text { Decimal Number }}{\text { (No. of input pulses) }}$

$\begin{array}{lllll}0 & 0 & 0 & 0 & 0 \\ 1 & 0 & 0 & 0 & 1 \\ 2 & 0 & 0 & 1 & 0 \\ 3 & 0 & 0 & 1 & 1 \\ 4 & 0 & 1 & 0 & 0 \\ 5 & 0 & 1 & 0 & 1 \\ 6 & 0 & 1 & 1 & 0 \\ 7 & 0 & 1 & 1 & 1 \\ 8 & 1 & 0 & 0 & 0 \\ 9 & 1 & 0 & 0 & 1 \\ 10 & 1 & 0 & 1 & 0 \\ 11 & 1 & 0 & 1 & 1 \\ 12 & 1 & 1 & 0 & 0 \\ 13 & 1 & 1 & 0 & 1 \\ 14 & 1 & 1 & 1 & 0 \\ 15 & 1 & 1 & 1 & 1 \\ 16 & 0 & 0 & 0 & 0\end{array}$

Examine table A for a moment. Consider the first few decimal number $0,1,2$, and 3. To use the decimal system of numbering in a computing device you would need to have 4 registers in order to record the information presented. Now, from the table, you can see that the binary system needs only two registers to represent

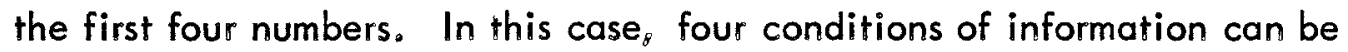
represented by the use of two registers. You now should be able to see where an on-off electronic system fits into the binary pattern very well. Say that you wish to indicate the decimal number in a computing function. This can be accomplished 
in the binary digital computer by representing it (from table A) as 0011 . The binary digits 0011 would be represented in a relay system by the two "1" relays being in the closed (go) condition.

Once again referring to the table $A$, you see that three registers of the binary system will enable you to represent eight pieces of information, four registers represent 16 pieces of information. By the time you have seven registers, you can represent 128 pieces of information.

D. BINARY COUNTERS TO A BASE OTHER THAN 2

From the previous discussion we have learned that to have a counter of 4 , we need 2 binaries, and for a counter of 8 , we need 3 binaries, and for a counter of 16 we need 4 binaries. Therefore, for a counter with $N$ number of binaries we may have a counter equal to $2^{N}$.

To make a counter other than that equal to a base of 2 , we take the output from the last binary and feed it back to the appropriate binary or binaries. Thus, to convert a counter of 16 into a counter of 10 , we feedback our 8th pulse to $B_{1}$ and $B_{2}$ ' changing the states of both binaries from a " 0 " state to a "1" state. The yth pulse will then fill all registers to a " 1 " state and the IOth pulse will reset it. A binary counter of 10 and its waveforms are represented in figure 4.

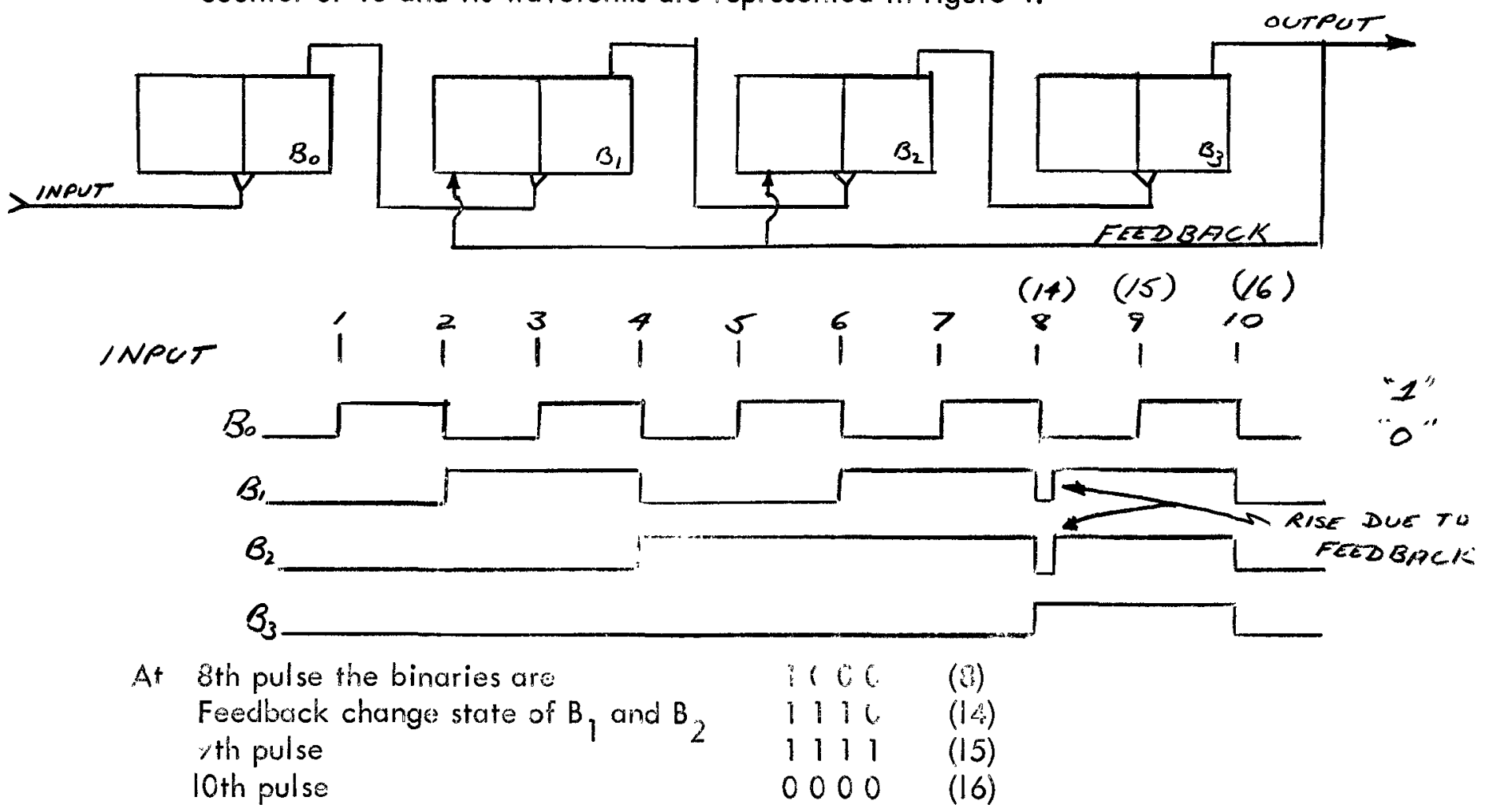

Figure 4 
To determine the feedback loops we use the following three steps:

1. Find the total count possible

2. Subtract from the total count the scale by which you prefer to count

3. Feedback unsymmetrically to the binaries that total the difference between the two scales.

Example:

1. We wish to have a counter of 10 .

$2^{3}=8$ and since 8 will not cover the count of 10 we try

$2^{4}=16$. We need 4 binaries. We wish to count by 10 so

we have $2^{4}=16$

$\begin{array}{r}-10 \\ \hline 6\end{array}$

Binary representation $2^{1} \times 1+2^{2} \times 1=6$. Therefore we feedback to binaries $B_{1}$ and $B_{2}$ to make a counter of 16 .

2. To make a counter of 41 :

$2^{5}=32$ and will not cover 41

$2^{6}=64$ and we therefore need 6 binaries

$=\frac{41}{23}$

Binary representation $2^{0} \times 1+2^{1} \times 1+2^{2} \times 1+2^{4} \times 1=23$.

Therefore we feed the 32nd pulse back to $\mathrm{B}_{0^{\prime}} \mathrm{B}_{1^{\prime}} \mathrm{B}_{2^{s}}$ and $\mathrm{B}_{4}$ changing the state of the counter from 32 to 55 and 9 pulses

later the counter completes one cycle. $(32+9=41)$

32nd pulse

$100000=32$

After feedback

$110111=55$

\section{E. APPLICATION OF COUNTERS}

I. Direct Counting

An early application of counters arose in connection with research into the properties of the nucleus of an atom. In order to determine the radioactivity 
of a source, it is necessary to count individually the emitted particles for a given time interval.

\section{Measurement of Frequency}

The basic principle by which counters are used for the precise determination of frequency $y_{B}$ is illustrated in figure 5.

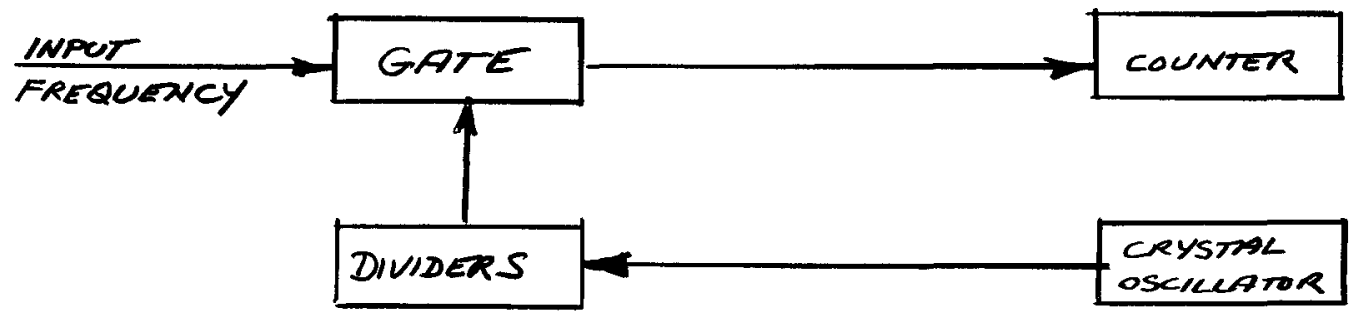

Figure 5

The input signal whose frequency is to be measured is converted into pulses and applied through a gate to an electronic counter.

3. Measurement of Time

The time interval between two pulses may also be measured with the circuit in figure 5. The first pulse could open the gate and the second pulse close the gate.

4. Measurement of Speed

A speed determination may be converted into a time measurement, if two photo cell-light-source combinations are set a fixed distance apart, the average speed of an object passing between these points is proportional to the time interval between the generated pulses.

5. Digital Computer

Counters constitute a basic building block in digital computers and are used to perform many functions such as storage.

6. Waveform Generation

The waveforms which occur at the plates or grids of binary counters may be combined with other circuits to generate complex pulse type waveforms. 
The next section will deal with basic digital computer circuits, binary dividers and some basic digital systems.

\section{REFERENCE:}

1. Millman - Taub "Pulse and Digital Circuits", McGraw-Hill, 1956

Here are a list of corrections that should be made to Section 1.

I. Page 3 - top paragraph

Figure 5695 should be 1695 .

2. Page 4 - Section B

Decimal 182 should be binary 10110110.

3. Page 6 - Section 3

$0 \times 1=0$. 